\title{
O SECRETÁRIO EXECUTIVO E A FLEXIBILIDADE COMPORTAMENTAL NO TRABALHO
}

\section{THE EXECUTIVE SECRETARY AND BEHAVIORAL FLEXIBILITY AT WORK}

\author{
Elisandréia Fontana Terra \\ Pós-graduação em Administração de Empresas pela Fundação Getúlio Vargas- \\ FGV \\ lisafontana@gmail.com
}

\section{Fernanda Harmitt Machado}

Mestre em Pedagogia da Motricidade Humana (Rio Claro) pela Universidade Estadual Paulista Júlio de Mesquita Filho

Professora das Faculdades Integradas Claretianas

profa.fernandahm@yahoo.com.br 


\section{RESUMO}

Este artigo tem como objetivo abordar a flexibilidade comportamental que é determinada pela capacidade de adaptação do indivíduo aos diversos perfis comportamentais que compõem o ambiente organizacional no qual ele está inserido. Ela é atribuída ao secretário executivo como uma habilidade profissional desejável devido à gama de pessoas com a qual ele se relaciona diariamente. Para isso, foi realizada uma pesquisa bibliográfica que possibilitou a discussão das ideias de autores especializados na temática, e uma pesquisa exploratória que utilizou a entrevista pessoal aplicada a quatro secretários; por meio da qual foi possível a descrição das situações reais cotidianas dos secretários executivos participantes. Os resultados mostraram que esse profissional valoriza a realização profissional como motivação e sentido do trabalho e que, diante dos diferentes tipos comportamentais dos indivíduos, a persistência em manter o clima organizacional agradável através da capacidade de flexibilização comportamental é essencial. Ainda, grande importância foi dada ao diálogo, por meio do qual todos podem expor suas queixas, elogios e tudo o que julgarem necessário a fim de identificar as ameaças e oportunidades, bem como maximizar os pontos positivos existentes, para que exista sempre harmonia no ambiente de trabalho.

Palavras-chave: Flexibilidade; Comportamento; Secretariado; Administração; Relacionamento. 


\section{ABSTRACT}

The goal of this article is to approach the behavioral flexibility determined by the individual's adaptation capability to the different behavioral profiles that compose the organizational environment in which they are inserted, which is a desired skill given the range of people they daily relate to. For this, a literature search has been performed and it has enabled a discussion of the ideas from authors specialized in this subject. Also an exploratory research has been made based on personal interviews applied to four secretaries, which enabled to describe real everyday situations of the participant executive secretaries. Results have shown that this professional values professional achievement as a motivation and meaning of work and that, given the different behavioral kinds of individuals, persistence to keep the organizational climate fine through behavioral flexibility is essential. Furthermore, great importance has been given to dialoguing, by which everyone may expose their complaints, praises and anything else deemed necessary to identify threats and opportunities and to maximize good points, so that there is always harmony in the workplace.

Keywords: Flexibility; Behavior; Secretary; Administration; Relationship. 


\section{INTRODUÇÃO}

Entre o período de julho a novembro de 2009, a FMR Consulting conduziu um estudo com o objetivo de identificar o perfil dos usuários de serviços bancários Private Banking cujo patrimônio supera U\$\$ 1 milhão.

Após compilar os dados da pesquisa, os participantes foram questionados sobre quem dentre os presentes no staff, equipe de funcionários, assessores de cada executivo entrevistado é mais confiável e "competente" para se delegar tarefas.

O resultado expôs que os secretários executivos são os mais confiáveis e identificou também que dos atributos mais valorizados nesse profissional, o equilíbrio emocional está em terceiro, o bom relacionamento com todos os níveis profissionais em quarto e a flexibilidade ou "jogo de cintura" em quinto lugar, informações destacadas para esta pesquisa, dentre outras como: autonomia e proatividade, senso total de confidencialidade e discrição e comunicação eficaz e clara com todos os níveis (PESSOA, 2010).

Assim, pode-se notar que a flexibilidade comportamental que o secretário executivo deve desenvolver continuamente ao longo de sua carreira, efetivamente, poderá ajudá-lo a obter melhor desempenho ao lidar com as adversidades profissionais e a aprimorar competências técnicas e de relacionamento $o$ que a torna ponto relevante desta profissão e consequentemente, de estudos da área.

\subsection{OBJETIVO}

No âmbito do trabalho, as condições ambientais são fatores importantes que implicam diretamente o desenvolvimento das atividades profissionais a serem desenvolvidas e tanto quanto influenciam, seus resultados são influenciados pela capacidade e "jogo de cintura" do profissional. Nesse sentido, o objetivo desta pesquisa é discutir as relações humanas do secretário executivo e os seus processos intervenientes positivos e negativos, derivados da personalidade, da conduta e do comportamento individual e coletivo. 


\section{METODOLOGIA}

Por melhor retratar a situação a ser apresentada, esta pesquisa de caráter qualitativo foi desenvolvida em dois momentos: no primeiro, foi elaborada uma pesquisa bibliográfica com o objetivo de identificação, apresentação e discussão das ideias de autores especializados na temática e, no segundo momento, optouse pela pesquisa exploratória, para identificação e descrição de situações reais sobre a temática.

Com a finalidade de identificar as situações reais vivenciadas no âmbito do trabalho por quatro secretários executivos, especificamente selecionados por exercerem a função há mais de uma década na diretoria do Instituto de Biociências da UNESP campus Rio Claro, onde a pesquisa exploratória foi desenvolvida para compor uma amostra qualitativa.

Procurou-se compreender as relações favoráveis ou dificultadoras do desenvolvimento de uma postura profissional flexível e favorável ao bom relacionamento interpessoal e bons resultados organizacionais.

Por meio de seus depoimentos, coletados em entrevistas semiestruturadas, que ao mesmo tempo conduzem a direção das informações a serem coletadas, sem limitar ou interferir nas opiniões apresentadas pelos entrevistados, procurou-se discutir o tema abordado na pesquisa bibliográfica, de maneira que possibilitou o reforço das teorias apresentadas.

\section{EMBASAMENTO TEÓRICO}

\subsection{AS CONDIÇÕES AMBIENTAIS E A PRODUTIVIDADE}

Segundo Chiavenato (1999), na década de 1930, o Conselho Nacional de Pesquisas dos Estados Unidos realizou uma pesquisa em Hawthorne, localizado em Chicago, com o objetivo de pesquisar o efeito que as condições ambientais provocavam na produtividade do trabalhador, para pôr à prova os preceitos da Administração Científica, modelo desenvolvido por Frederick Winslow Taylor (1856-1915), no início do séc. XX, conhecida também como Taylorismo, cuja 
característica tem ênfase nas tarefas, objetivando o aumento da eficiência ao nível operacional.

Seguem as principais conclusões obtidas por meio desta pesquisa: na primeira, o trabalho é uma atividade tipicamente grupal, o indivíduo é influenciado pelas normas do grupo e não apenas pelos incentivos salariais da organização; na segunda, o operário não reage como indivíduo isolado, mas como membro de um grupo e em estreita relação de camaradagem e integração com os colegas; na terceira conclusão apresentada, a tarefa da administração é formar chefes capazes de compreender e de comunicar, com elevado espírito democrático e que sejam persuasivos e simpáticos e por último; a pessoa é motivada essencialmente pela necessidade de "estar junto" com outras pessoas, de ser reconhecida pelos outros e receber adequada comunicação. (CHIAVENATO, 1999)

Desta maneira, o conceito de o trabalhador preocupar-se essencialmente com objetivos salariais e materiais, chamado de homo economicus, da Administração Científica, foi substituído pelo conceito de homo social.

Neste contexto, vale ainda evidenciar a questão de o relacionamento interpessoal e as condições ambientais terem peso relevante no resultado final de um trabalho, o que é tido como de grande importância, mas não é amplamente estudado e divulgado nos meios empresarias, possivelmente pela complexidade que ele apresenta, pois cada personalidade, que permeia essas relações, é um fator complexo e é como a impressão digital, única, afirma Lobos (2000).

Lobos (2000) diz que essa complexidade e a dificuldade de se investir em melhorias nos relacionamentos interpessoais ao longo prazo é o que faz com que as empresas acreditem que é mais prático simplificar as coisas em duas categorias, como: certo ou errado e bom ou ruim para interpretar e "controlar" cada ser humano, do que dar importância a cada detalhe do comportamento individual e estabelecer padrões de comportamento organizacional desejáveis.

Pode-se ainda dizer que a diversidade do comportamento humano é fator de peso nas relações humanas, inclusive nas profissionais, sendo evidenciada na função do secretário executivo, que tem como premissa de sua função as relações humanas. E, por apresentar tamanha importância, é objeto de pesquisa para estudiosos que ao longo dos tempos buscam compreendê-la e explicá-la - o que justifica esta pesquisa.

Revista de Gestão e Secretariado, São Paulo, v. 2, n. 2, p.105-120, jul./dez. 2011. 
Para entender a capacidade de flexibilização comportamental no ambiente profissional é necessário que sejam compreendidos os processos determinantes da construção da cultura organizacional e a sua influência sobre as ações individuais neste ambiente. A cultura organizacional funciona como reflexo das crenças, valores, comportamento e ações organizacionais, é um fator que direciona as ações dos grupos organizacionais, e pode favorecer ou não a flexibilidade comportamental.

Nesse sentido, Kanaane (1999) diz que a cultura organizacional é composta por três dimensões: a dimensão material é o sistema produtivo, a psicossocial é o sistema de comunicação e interação dos envolvidos e por fim, a ideológica é o sistema de valores vigentes na organização.

\subsection{ESTUDOS SOBRE A DIVERSIDADE DO COMPORTAMENTO HUMANO}

Existem explicações com raízes antigas para diversidade comportamental discutida que, na mitologia grega relacionava deuses para tentar explicar as características peculiares do comportamento humano. Dessa maneira, Apolo simbolizava o Espírito; Prometeu, a Ciência; Dionísio, o Prazer e Epimeteu, o Dever (LOBOS, 2000), o que revela que os pensadores dessa época remota já se sentiam incomodados com a questão das determinantes do comportamento humano que naquele dado momento ainda eram tidas como algo a ser desvendado.

osteriormente, Hipócrates, o grego considerado o pai da medicina, distinguiu quatro temperamentos humanos: o Sanguíneo, cujo significado remete ao "sangue" e pode-se entender como "vida"; o Melancólico, palavra que deriva de "melancolia" e pode ser entendida como "tristeza"; o Colérico, que significa "ira" ou "cólera" e por fim o Fleumático, que deriva da palavra "fleuma" e pode ser entendido como ausência de emoção (LOBOS, 2000).

Esses quatro temperamentos, ainda hoje são amplamente utilizados em estudos sobre a temática. Assim, pode-se dizer que este tema desperta a curiosidade e a necessidade de, como um código, ser decifrado, pelo fato de muitas vezes ser determinante nas escolhas e formação das opiniões humanas diárias. 
Também, um ano antes de Cristo foi descoberto um desenho geométrico simbolizando nove tipos da personalidade humana, denominado eneagrama cuja autoria é atribuída aos Sufis, uma seita islâmica (LOBOS, 2000).

Na era moderna, a diversidade psicológica é estudada por dois ângulos: o psicanalítico e o psiconeurológico. Segundo Lobos (2000), Roger Sperry foi o primeiro dos psiconeurologistas a constatar que o lado esquerdo do cérebro comanda o raciocínio lógico e as atividades objetivas como: ler, escrever e sequenciar e o lado direito, a intuição e a capacidade de abstração. Ned Herrmann, psiconeurologista moderno, em seu estudo, divide o cérebro em quatro partes, distinguindo quatro regiões responsáveis por funções diferentes. A mais evoluída em uma pessoa é a que irá determinar o seu modo de ser. Então, apoiado nessa descoberta, criou o Brain Dominance Instrument (HBDI), um teste que mede a preferência de pensamento da pessoa (LOBOS, 2000).

Embora não exista um padrão de comportamento oficialmente tido como certo ou errado, existem os comportamentos mais aceitos em cada ambiente e ocasião, o que será determinado e evidenciado pelo relacionamento interpessoal. À medida que este vai se desenvolvendo, o nível de satisfação dos envolvidos no grupo aumenta simultaneamente com a sua positividade, seja este grupo pertencente a um colégio, à família, à turma de amigos ou a uma empresa como no caso deste estudo, em especial ao profissional secretário executivo.

\subsection{ESTUDOS SOBRE A DIVERSIDADE DO COMPORTAMENTO EXECUTIVO}

Como resultado de estudos sobre o comportamento executivo, o modelo ad hoc, Modelo dos Quatro Tipos, apresentado por Lobos (2000), revela tipos executivos bem representativos e específicos.

Segundo seu estudo, em cada pessoa, na condição executiva, existe um tipo de comportamento predominante.

Quanto à fonte de informação, pode ser introvertido, isto é, voltado para si mesmo ou extrovertido, voltado para mundo externo. Quanto ao modo de obter a informação, pode ser sensorial, isto é objetivo, utiliza dados específicos; ou intuitivo, isto é, utiliza da imaginação, trabalha com possibilidades.

Quanto à maneira de decidir, pode ser pensador, que utiliza da lógica, é racional; ou sentimental, que decide considerando o valor humano. E finalmente, 
quanto à postura pessoal, como julgador que se caracteriza por ser estruturado, metódico e toma decisões rapidamente; e o perceptivo, que é volúvel e não decide de imediato (LOBOS, 2000).

Para Lobos (2000), o que diferencia os executivos na tomada de decisões, é a forma de raciocínio, denominada "pensar" e a forma de lidar com as circunstâncias, denominada "julgar". Segundo Meyers \& Briggs, a forma executiva de pensar ou julgar tem relação com o fato de esses profissionais serem introvertidos ou extrovertidos e sensoriais ou intuitivos, conforme ilustrado na Figura 1.

Figura 1 - Características Psicológicas (LOBOS, 2000, p. 13).

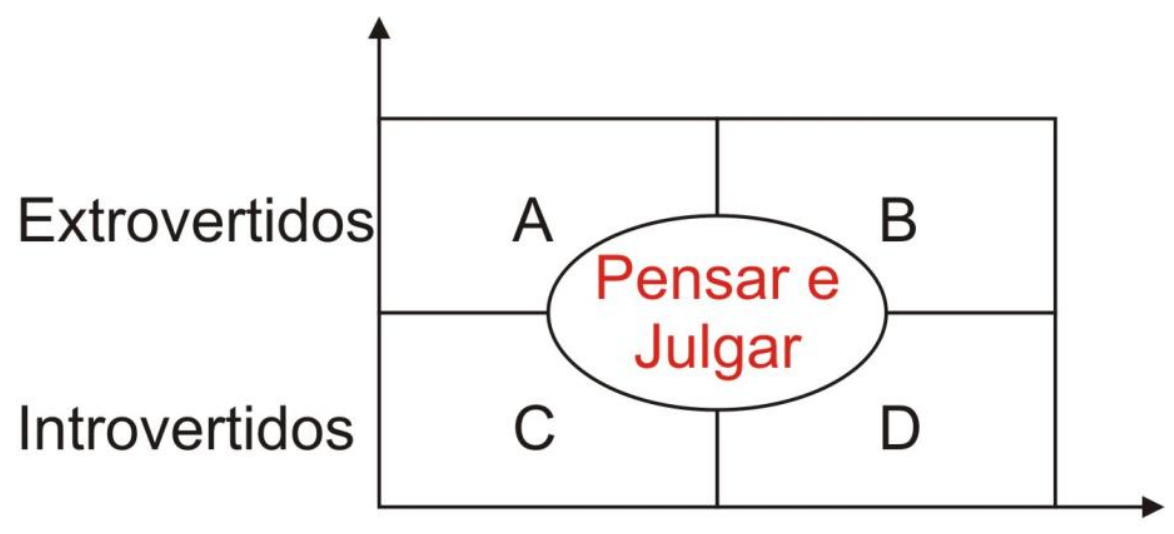

\section{Sensoriais Intuitivos}

De acordo com Lobos (2000), através da classificação feita por Meyers \& Briggs, que determina a questão de personalidade executiva, fica mais simples a sua compreensão, mas não é suficiente para caracterizar os executivos, pois esta classificação não explica a questão por completo. "Equivale a definir um atleta apenas pelo seu peso e altura! Sem conhecer o seu biotipo, equilíbrio energético, estrutura emocional etc." (LOBOS, 2000, p.14).

Segundo Lobos (2000), a função do executivo é tomar decisões e para isso é necessário raciocinar, planejar etc. O que os diferencia são as forças que os motivam, mobilizam e Ihes dão vida como tomadores de decisões. Estas forças são chamadas por ele de "Energia e Desejo".

A Energia existe dentro de cada indivíduo desde quando ele nasce, é como um fogo interior que Ihe dá a propulsão inicial que ora o ilumina, ora o consome, contudo a Energia deve ser, de alguma forma, ativada. O Desejo é 
uma fonte que "mantém o indivíduo em movimento em prol de um objetivo" (LOBOS, 2000, p.15).

Os executivos, como tomadores de decisões e implantadores de mudanças, precisam de apoio até mesmo como determinante de sua Energia e Desejo e continuamente o secretário atua de forma relevante a oferecer suporte ao executivo para que as tarefas sejam desempenhadas de forma sábia e eficaz.

A Energia e o Desejo do executivo podem ser determinados pelo Trabalho em si: conhece a tarefa e a realiza corretamente, ou pelo Sucesso, "cuja medida é dada por terceiros, quer seja aplaudindo, ou vaiando" (LOBOS, 2000, p.14). "Dever e Paixão; Trabalho em si e Sucesso são focos de atenção do indivíduo e não estados de ânimo" (LOBOS, 2000, p.15).

O modelo teórico criado por Lobos (2000), exibido na Figura 2, é um modelo preliminar de classificação de executivos. Trata-se de uma tentativa de explicar as dimensões de Energia e Desejo correlacionando-as para que seja possível descrever, relacionar e comparar os quatro tipos psicológicos discutidos.

Figura 2 - Um modelo preliminar de classificação dos executivos (LOBOS, 2000, P. 15)

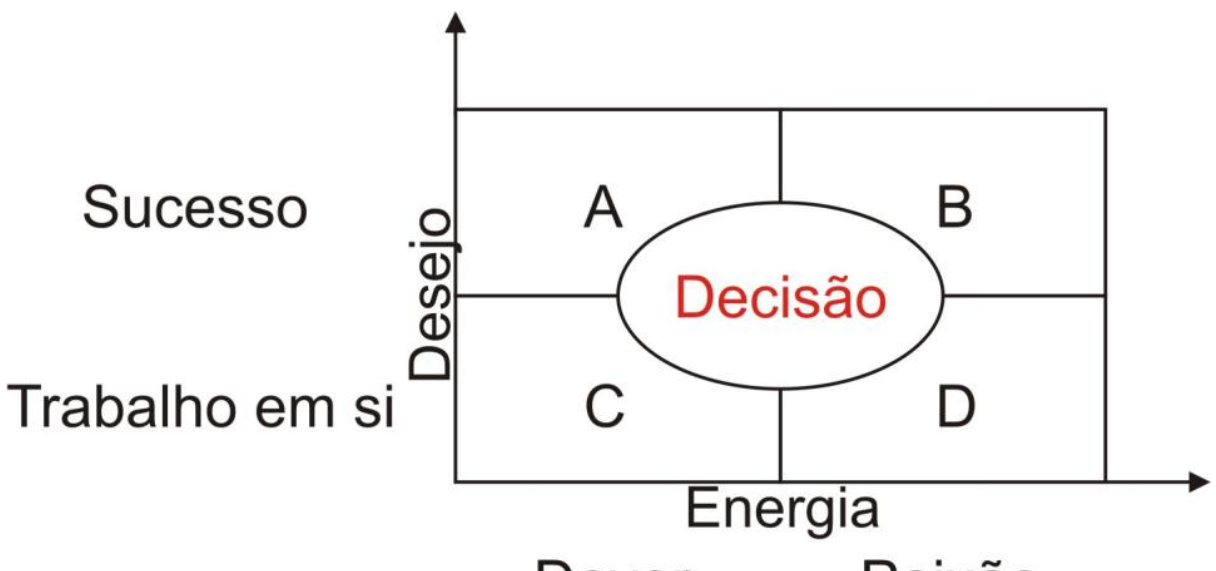

Dever Paixão 
A Figura 3 se refere ao Modelo dos Quatro Tipos, desenvolvido por Júlio Lobos, que define os quatro tipos de personalidades executivas determinadas a partir de suas fontes de Desejo e de Energia. Acompanhe a Figura 3:

Figura 3 - 0 Modelo dos Quatro Tipos (LOBOS, 2000, p.20)

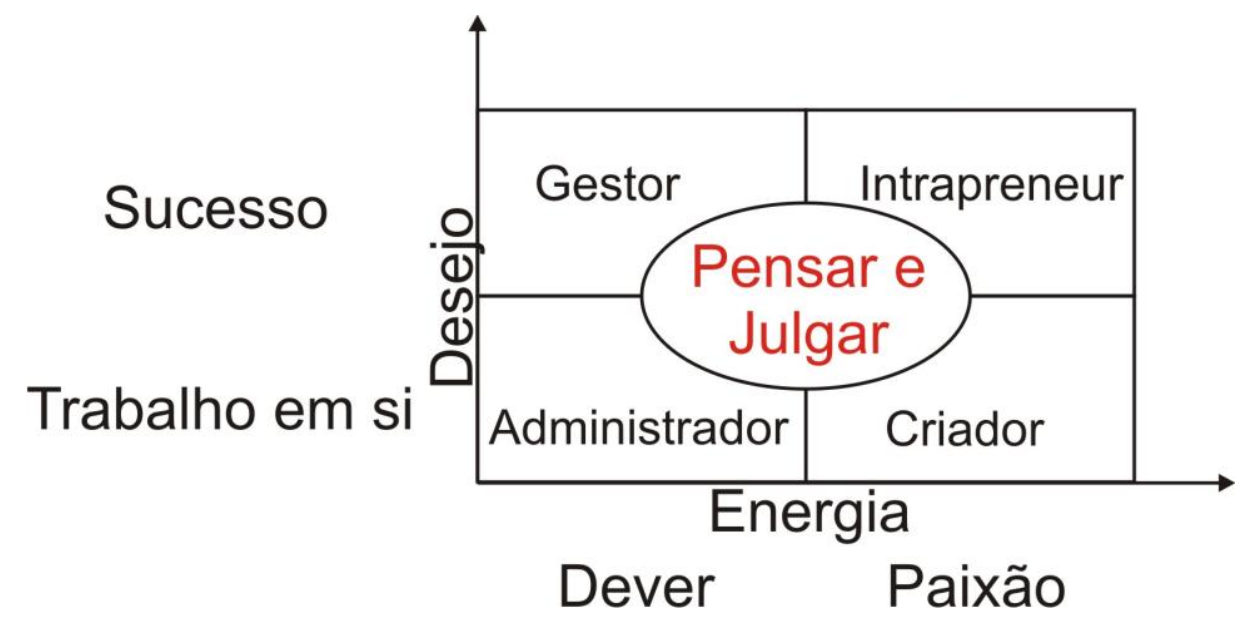

"Os quatro tipos psicológicos têm em comum as preferências psicológicas relacionadas à sua razão de ser, que é tomar decisões" (LOBOS, 2000, p.20). "

Porém, é necessário que cada executivo mostre um nível mínimo de raciocínio, lógica e capacidade de planejamento para que ele se qualifique. É importante também, neste momento e para os propósitos desta pesquisa, relembrar o papel do secretário executivo interagindo efetivamente com a personalidade executiva para a construção de resultados profissionais qualitativos.

Os estudos citados propõem possíveis explicações para o fato de as pessoas responderem de modos diferentes ao mesmo estímulo, enfatizando a necessidade de desenvolvimento de uma postura flexível e adaptável para o sucesso.

Neste sentido, o secretário executivo, por relacionar-se continuamente com uma gama diversificada de pessoas, como chefias, colegas de mesmo nível hierárquico e, muitas vezes com subordinados da sua área de atuação; a habilidade de esquivar-se de situações adversas deve ser sempre uma aliada.

Revista de Gestão e Secretariado, São Paulo, v. 2, n. 2, p.105-120, jul./dez. 2011. 
Para os que possuem essa habilidade naturalmente, basta aprimorá-la, mas os que possuem habilidades técnicas e são resistentes à flexibilidade comportamental, estão diante de um dificultador do bom desempenho profissional, que deve ser superado.

\subsection{AS AÇÕES INDIVIDUAIS E AS POSSIBILIDADES DE FLEXIBILIZAÇÃO DO COMPORTAMENTO}

De acordo com Kanaane (1999), não se pode tirar conclusões sobre um indivíduo baseando-se somente em suas ações, pois as ações são resultantes de um complexo processo e sofrem influência das circunstâncias.

Diante de uma situação ou pessoa, o indivíduo, ao assumir uma atitude, sofre influência de todos os seus valores, crenças, sentimentos, pensamentos, cognições e tendências à reação que acumula ao longo da vida, afirma Kanaane (1999).

No âmbito empresarial ocorrem situações em que o secretário executivo não tem seu comportamento refletido necessariamente em suas atitudes ou predisposição para ação, uma vez que se vê impelido de agir de acordo com as expectativas do chefe ou dos componentes do grupo.

Desta maneira, procura desempenhar os papéis sociais que são padrões esperados e tidos como corretos que correspondem ao que o grupo espera dele, distanciando-se de seus impulsos reais. Essa capacidade pode estar sendo determinada por sua habilidade de adaptação comportamental às necessidades e circunstâncias apresentadas e pode ser desenvolvida.

As pessoas se adaptam psicologicamente ao ambiente onde estão inseridas com o intuito de sobreviver, dominar, progredir etc., afirma Lobos (2000).

A flexibilização do comportamento do secretário executivo é que vai permitir que ele adapte o seu comportamento profissional às demandas do trabalho. E, com o auxílio de algumas estratégias, é possível identificar as diferenças comportamentais das pessoas com as quais se convive e saber administrar tais diferenças redundará no melhor convívio com o colega, o chefe e o subordinado, gerando uma grande oportunidade de crescimento conjunto. 
Nesse sentido e concordando com Lobos (2000, p. 10) "Conviver com pessoas diferentes no trabalho, todavia, pode ser transformado numa oportunidade de progresso...". "Flexibilizar é, todavia, uma prática alheia à nossa maneira se ser. Significa abrir mão do que se quer fazer em benefício de outra pessoa" (LOBOS, 2000, p. 73).

Para que exista uma melhor administração dos conflitos e flexibilização adequada é importante que se faça uma ponderação dos valores e comportamento pessoais de cada membro da equipe, permitindo que se desenvolvam habilidades para lidar com as diferenças identificadas entre cada indivíduo. O secretário executivo, devido à natureza interativa de sua função, tem um grande material de análise comportamental em mão, que poderá auxiliálo no processo de flexibilização: o contato pessoal.

\subsection{A PESQUISA EXPLORATÓRIA}

As seis questões aplicadas e analisadas por meio de entrevista pessoal e individual com quatro secretários executivos selecionados possibilitaram 0 reforço das teorias apresentadas na pesquisa bibliográfica.

Ao analisar as respostas dos entrevistados, ficou evidente à pesquisa que $100 \%$ consideram a realização profissional e a satisfação pelo trabalho realizado com sucesso como o fator que os impulsionam para o alto desempenho.

Quanto ao perfil ideal de liderança, ficou evidente que embora não tendo escolha, procuram adaptar-se ao perfil de liderança do superior direto; gostam que ele seja amigável e bem humorado e que confie, reconheça e valorize o trabalho executado. Sentem-se bem ao trabalhar com chefe exigente, pois o desafio de se fazer uma tarefa que exige melhor habilidade é uma oportunidade de crescimento, e, ao contrário, enfatizaram que não apreciam o chefe autoritário e antipático, que delega um trabalho sem confiar plenamente na competência do secretário executivo.

Os entrevistados gostam de pessoas que tenham espírito de cooperação com a equipe, que tenham flexibilidade e poder de decisão segura ao mesmo tempo.

Sentem-se melhor com pessoas que conseguem ser amigáveis e bem humoradas, não deixando de ser responsáveis e comprometidas com o trabalho, 
e não gostam de trabalhar com pessoas descontraídas em excesso, nem com as caladas, desatentas e acomodadas, que não valorizam o trabalho.

Quanto ao sentido do trabalho, em primeiro lugar enfatizaram a autorrealização e, em segundo, o reconhecimento financeiro; e afirmaram que a estratégia utilizada para melhora desse processo é o diálogo, citado como fundamental. Importante também procurar ser maleável, atencioso, prestativo e simpático com todas as pessoas e estar atento a tudo o que ocorre ao seu redor.

Sobre o auxílio da chefia no processo de adaptação, o diálogo foi novamente destacado, pois por meio dele a chefia pode identificar a existência de algum problema ou dificuldade e oferecer a ajuda que cabe à situação e, se for viável, procurar ajuda externa, como um curso de capacitação.

\subsection{RESULTADOS}

Por meio da pesquisa exploratória verificou-se que o ambiente de trabalho e a flexibilização comportamental dos que compõem este espaço influenciam diretamente no resultado final dos processos diários das organizações. Essa influência pode ser positiva ou negativa.

Não é possível fazer escolha do perfil das pessoas com quem se trabalha, e isso é bom, pois promove da diversidade. Conviver com as diferenças de atitudes e comportamento pode ser enriquecedor àqueles que souberem tirar bom proveito.

Do exposto, reforça-se que a flexibilidade comportamental favorece a relação interpessoal e deve ser desenvolvida de maneira que considere os próprios valores e os valores dos demais indivíduos envolvidos, a fim de proporcionar um crescimento conjunto que permita a cada um aceitar o outro e ao mesmo tempo manter a sua própria integridade.

\section{CONSIDERAÇÕES FINAIS}

A pesquisa exploratória confirma a literatura apresentada pela pesquisa bibliográfica. E para maior exploração do assunto, sugere-se ainda uma continuidade deste estudo por meio de aplicação da entrevista semiestruturada a 
secretários de outras instituições com a finalidade de analisar as possíveis diferenças de resultados alcançados e desenvolver ferramentas eficazes a favor da flexibilidade comportamental do secretário executivo nas organizações para viabilizar uma melhor qualidade de vida dentro e fora do âmbito organizacional.

\section{REFERÊNCIAS}

CHIAVENATO, Idalberto. Administração nos novos tempos. 14 ed. Rio de Janeiro: Campus, 1999.

KANAANE, Roberto. Comportamento humano nas organizações: o homem rumo ao século XXI. 2 ed. São Paulo: Atlas, 1999.

LOBOS, Julio. A Personalidade executiva: o passaporte para a gestão por competência e desenvolvimento de equipes. São Paulo: Negócios, 2000.

PESSOA A. Pesquisa traz visão de altos executivos sobre profissionais de Secretariado. Revista Excelência. Ano 8, n 25, 2010, pp. 10-12.RAUL. M. J. \& P. Nelson.

THIOLLENT, Michael. Metodologia da pesquisa-ação. 16 ed. São Paulo: Cortez, 2008.

Data do recebimento do artigo: 17/09/2011

Data do aceite de publicação: 13/12/2011 


\section{Anexo I}

Roteiro de perguntas aplicadas em entrevista aos secretários colaboradores:

1. O que mais te motiva para o alto desempenho?

2. Com qual perfil de liderança você prefere trabalhar e com qual tem mais dificuldade ou não gosta de trabalhar.

3. Com qual perfil de equipe ou de colega de trabalho você prefere trabalhar e com qual tem mais dificuldade ou não gosta de trabalhar?

4. Qual é o sentido do seu trabalho para você?

Reconhecimento Financeiro ( ）, Socialização ( ), Desafio ( ), Realização

( ), Aprendizado ( ) ou outros ( ). Se outros, explique.

5. Explique suas estratégias de adaptação aos diversos tipos de comportamento experimentados no ambiente organizacional.

6. Como sua chefia pode auxiliar nesse processo de adaptação?

Revista de Gestão e Secretariado, São Paulo, v. 2, n. 2, p.105-120, jul./dez. 2011. 